\title{
Marine mimivirus relatives are probably large algal viruses Adam Monier ${ }^{1}$, Jens Borggaard Larsen ${ }^{2}$, Ruth-Anne Sandaa ${ }^{2}$, Gunnar Bratbak ${ }^{2}$, Jean-Michel Claverie ${ }^{1}$ and Hiroyuki Ogata*1
}

\author{
Address: ${ }^{1}$ Structural and Genomic Information Laboratory, CNRS-UPR 2589, IBSM, Parc Scientifique de Luminy, 163 avenue de Luminy, Case \\ 934, 13288 Marseille Cedex 9, France and ²Department of Biology, University of Bergen, PO Box 7800, N-5020 Bergen, Norway \\ Email: Adam Monier - adam.monier@igs.cnrs-mrs.fr; Jens Borggaard Larsen - Jens.Larsen@bio.uib.no; Ruth- \\ Anne Sandaa - ruth.sandaa@bio.uib.no; Gunnar Bratbak - Gunnar.Bratbak@bio.uib.no; Jean-Michel Claverie - jean- \\ michel.claverie@univmed.fr; Hiroyuki Ogata* - Hiroyuki.Ogata@igs.cnrs-mrs.fr \\ * Corresponding author
}

Published: 23 January 2008

Virology Journal 2008, 5:12 doi:10.1186/1743-422X-5-12

This article is available from: http://www.virologyj.com/content/5/I//2

(C) 2008 Monier et al; licensee BioMed Central Ltd.

This is an Open Access article distributed under the terms of the Creative Commons Attribution License (http://creativecommons.org/licenses/by/2.0), which permits unrestricted use, distribution, and reproduction in any medium, provided the original work is properly cited.
Received: 9 November 2007

Accepted: 23 January 2008

\begin{abstract}
Background: Acanthamoeba polyphaga mimivirus is the largest known ds-DNA virus and its 1.2 Mb-genome sequence has revealed many unique features. Mimivirus occupies an independent lineage among eukaryotic viruses and its known hosts include only species from the Acanthamoeba genus. The existence of mimivirus relatives was first suggested by the analysis of the Sargasso Sea metagenomic data.
\end{abstract}

Results: We now further demonstrate the presence of numerous "mimivirus-like" sequences using a larger marine metagenomic data set. We also show that the DNA polymerase sequences from three algal viruses (CeVOI, PpVOI, PoVOI) infecting different marine algal species (Chrysochromulina ericina, Phaeocystis pouchetii, Pyramimonas orientalis) are very closely related to their homolog in mimivirus.

Conclusion: Our results suggest that the numerous mimivirus-related sequences identified in marine environments are likely to originate from diverse large DNA viruses infecting phytoplankton. Micro-algae thus constitute a new category of potential hosts in which to look for new species of Mimiviridae.

\section{Background}

The discovery of Acanthamoeba polyphaga mimivirus was a significant breakthrough in the recent history of virology. Both mimivirus particle size $(\sim 750 \mathrm{~nm})$ and its genetic repertoire (1.2 Mb-genome encoding 911 protein coding genes) are comparable to those of many parasitic cellular organisms $[1,2]$. This giant virus exhibits several genes for translation system components [3], and its particle contains both DNA and RNA molecules [2]. These features both quantitatively and qualitatively challenge the boundary between viruses and cells, and reignited a smol- dering debate about the origin of viruses and their role in the emergence of eukaryotes [4-9].

Mimivirus belongs to Nucleocytoplasmic large DNA viruses (NCLDVs) [10]. From its basal position in the phylogenetic trees based on conserved NCLDV core genes $[1,2]$, the new "Mimiviridae" family was proposed for mimivirus [11]. NCLDVs now include Mimiviridae, Phycodnaviridae, Iridoviridae, Asfarviridae and Poxviridae. Mimivirus is the sole member of the Mimiviridae family. The lack of known close relatives of mimivirus makes it diffi- 
cult to build the evolutionary history of its surprising features. Is mimivirus one of many eccentric creatures in nature such as Rafflesia, a parasitic plant in southeastern Asia known for its gigantic flower [12]? Are the mimivirus extraordinary characteristics linked to the origin of eukaryotes [5]? Clearly, appraising the actual biological significance of this exceptional virus requires the isolation and characterization of additional members of the Mimiviridae family.

Mimivirus was initially isolated in amoebae sampled from the water of a cooling tower. Following the circumstances of its discovery, mimivirus was suspected to be a causative agent of pneumonia [13]. The presence of antibodies recognizing mimivirus in the sera of patients with community or hospital-acquired pneumonia was reported [14,15]. However, no serological evidence of mimivirus infection was found in hospitalized children in Austria [16] and mimivirus has never been isolated from an infected patient despite numerous attempts. In the laboratory, mimivirus appears to infect only species of Acanthamoeba [17]. Acanthamoeba are ubiquitous in nature and they have been isolated from diverse environments including freshwater lakes, river waters, salt water lakes, sea waters, soils and the atmosphere $[18,19]$. Mimivirus relatives might thus exist everywhere.

Ghedin and Claverie identified sequences similar to mimivirus genes in the environmental sequence library from the Sargasso Sea [20]. This strongly suggested the existence of mimivirus relatives in the sea. More recently, we found numerous additional "mimivirus-like" sequences in the much larger metagenomic data set generated by the Global Ocean Sampling Expedition (hereafter referred to as GOS data; [21]) (Monier et al., manuscript in preparation). However, the analysis of metagenomic data (i.e. short sequences from unknown and mixed organisms) provides no insights into the hosts susceptible to harbor the putative new species of Mimiviridae corresponding to these sequences.

While continually monitoring the new occurrences of mimivirus-like sequences in public databases, we recently noticed that the type B DNA polymerase (hereafter referred to as PolB) sequences of three lytic viruses from Norwegian coastal waters were very similar to the PolB sequence of mimivirus. The three viruses [CeV01 (GenBank accession: ABU23716), PpV01 (스23718), PoV01 (ABU23717)] were isolated from diverse marine unicellular algae: Chrysochromulina ericina, Phaeocystis pouchetii and Pyramimonas orientalis, respectively $[22,23]$. C. ericina and $P$. pouchetii are both haptophytes but phylogenetically distant and classified in different orders, i.e. Prymnesiales and Phaeocystales. P. pouchetii forms dense and almost monospecific spring blooms while C. ericina thrive in mixed flagellate communities and at cell densities usually not attaining bloom levels $[24,25]$. P. orientalis is a prasinophyte belonging to the green algae. It has a worldwide distribution but the abundance is most often low with no significant contribution to the overall phytoplankton biomass $[26,27]$. The three algal viruses infecting these phytoplankters have all been classified as phycodnaviruses.

In this report, we first analyzed the distribution of mimivirus-like sequences found in the GOS data and mapped them on the mimivirus genome. We then performed phylogenetic analyses which indicated a very close relationship between the PolB sequences of mimivirus and the three algal viruses (CeV01, PpV01, PoV01), as well as with their homologs from the metagenomic data set.

\section{Results}

We first examined the presence of "mimivirus-like" sequences in the GOS data composed of 7.7 million sequencing reads. Based on a protocol similar to the one used by Ghedin and Claverie [20], we identified 5,293 open reading frames (ORFs; $\geq 60$ aa) that are closely related to protein sequences encoded in the mimivirus genome. Of 911 mimivirus protein coding genes, 229 $(25 \%)$ showed closely related sequences in the GOS data. The distribution of the number of GOS matches for each of the 229 mimivirus genes is highly variable ranging from 1 to 249 (ex. 249 hits for MIMI_R555 DNA repair protein). These 229 mimivirus genes are distributed widely along the chromosome, with an apparently higher concentration in the central part of the genome (Fig. 1). This part of the genome encodes many conserved genes including most of the NCLDV core genes [2]. Mimivirus possesses 26 NCLDV core genes (class I, II and III), of which 17 had close homologs in the GOS data (Table 1 and Additional File 1). Phylogenetic trees for the homologs of two class I core genes (L437, VV A32-type virion packaging ATPase; L206/L207, VV D5-type ATPase) confirmed the separate grouping of the mimivirus sequences with their closest homologs found in the GOS data (Fig. 2) Among the translation related genes of mimivirus, mRNA cap binding protein gene (MIMI_L496) and translation initiation factor eEF-1 gene (MIMI_R624) had close homologs in the GOS data. Remarkably, 55 of the 229 mimivirus genes exhibiting a strong similarity in the GOS data, correspond to ORFans (i.e. ORFs lacking homologs in known species), further suggesting that their GOS homologs belong to viruses closely related to mimivirus.

We next selected fourteen mimivirus PolB-like GOS-ORF sequences that are long enough to be fully aligned with homologs from different viruses including three algal viruses, CeV01, PpV01 and PoV01. PolB sequences from CeV01 (GenBank: ABU23716), mimivirus [28] and Heter- 
Table I: A selected list of mimivirus genes with closely related sequences in the GOS data.

\begin{tabular}{|c|c|c|}
\hline Mimivirus ORF & Annotation & $\begin{array}{l}\text { Number of "mimivirus-like" sequences in } \\
\text { the GOS data }\end{array}$ \\
\hline \multicolumn{3}{|c|}{ NCLDV class I core genes } \\
\hline MIMI_L206 * & Helicase III/VV D5-type ATPase (C-term) & 139 \\
\hline MIMI_L207 * & Helicase III/VV D5-type ATPase (N-term) & 90 \\
\hline MIMI_R322 & DNA polymerase (B family) & 185 \\
\hline MIMI_R350 & $\begin{array}{l}\text { putative transcription termination factor, } \mathrm{VV} \\
\text { D6R helicase }\end{array}$ & 90 \\
\hline MIMI_L396 & VV AI8 helicase & 138 \\
\hline MIMI_R400 & $\mathrm{S} / \mathrm{T}$ protein kinase & 32 \\
\hline MIMI_L425 & Major capsid protein & 7 \\
\hline MIMI_L437 & VV A32 virion packaging ATPase & 71 \\
\hline MIMI_R450 & AIL transcription factor & 28 \\
\hline MIMI_R596 & Thiol oxidoreductase EIOR & 7 \\
\hline \multicolumn{3}{|c|}{ NCLDV class II core genes } \\
\hline MIMI_R339 & TFII-like transcription factor & 3 \\
\hline MIMI_R493 & Proliferating Cell Nuclear Antigen & 45 \\
\hline \multicolumn{3}{|c|}{ NCLDV class III core genes } \\
\hline MIMI_L244 & Rpb2 & I \\
\hline MIMI_L364 & SWI/SNF2 helicase (MSV224) & 54 \\
\hline MIMI_R382 & mRNA Capping Enzyme & 189 \\
\hline MIMI_R429 & PBCVI-A494R-like, 9 paralogs & 145 \\
\hline MIMI_R480 & Topoisomerase II & 1 \\
\hline MIMI_R50I & Rpbl & 14 \\
\hline \multicolumn{3}{|l|}{ Translation } \\
\hline MIMI_L496 & $\begin{array}{l}\text { Translation initiation factor 4E, (mRNA cap } \\
\text { binding) }\end{array}$ & 11 \\
\hline MIMI_R624 & GTP binding elongation factor eF-Tu & 3 \\
\hline \multicolumn{3}{|l|}{ DNA repair } \\
\hline MIMI_L3I5 & $\begin{array}{l}\text { Hydrolysis of DNA containing ring-opened N7 } \\
\text { methylguanine }\end{array}$ & 58 \\
\hline MIMI_L359 & DNA mismatch repair ATPase MutS & 44 \\
\hline MIMI_R406 & Alkylated DNA repair & 3 \\
\hline MIMI_L687 & $\begin{array}{l}\text { Endonuclease for the repair of UV-irradiated } \\
\text { DNA }\end{array}$ & 2 \\
\hline MIMI_R693 & $\begin{array}{l}\text { Methylated-DNA-protein-cysteine } \\
\text { methyltransferase }\end{array}$ & 9 \\
\hline \multicolumn{3}{|c|}{$\begin{array}{l}\text { Other genes with more than } 100 \\
\text { matches }\end{array}$} \\
\hline MIMI_L250 & putative transcription initiation factor IIB & 143 \\
\hline MIMI_L25I & Lon domain protease & 110 \\
\hline MIMI_R303 & NAD-dependent DNA ligase & 163 \\
\hline MIMI_R325 & $\begin{array}{l}\text { Metal-dependent hydrolase (Chilo iridescent } \\
\text { virus I36R) }\end{array}$ & 136 \\
\hline MIMI_R354 & Lambda-type exonuclease & 147 \\
\hline MIMI_R355 & Unknown & 150 \\
\hline MIMI_L375 & Unknown & 130 \\
\hline MIMI_L377 & putative NTPase I & 133 \\
\hline MIMI_R409 & Unknown & 155 \\
\hline MIMI_L434 & Unknown & 103 \\
\hline MIMI_R453 & TATA-box binding protein (TBP) & $|3|$ \\
\hline MIMI_L454 & Unknown & 119 \\
\hline MIMI_R555 & putative DNA repair protein & 249 \\
\hline MIMI_R563 & $\begin{array}{l}\text { Contains helicase conserved C-terminal } \\
\text { domain (PFAM) }\end{array}$ & 118 \\
\hline
\end{tabular}

* Two ORFs (L206, L207) have been recently merged into a single ORF after the re-sequencing of the genomic region (SWISS-PROT: Q5UQ22, Stéphane Audic, personal communication). 


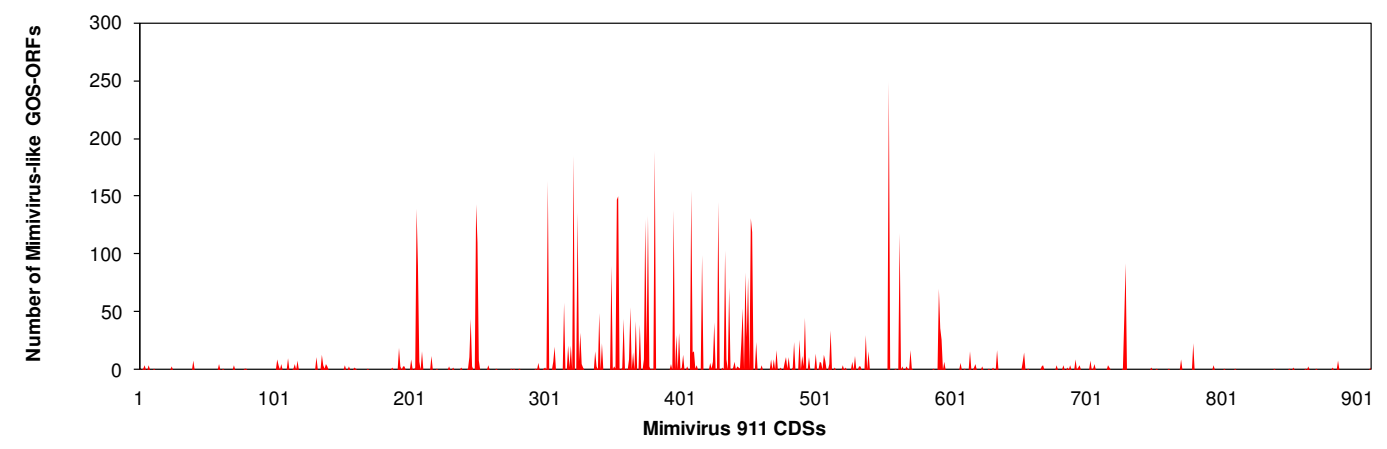

Figure I

Mimivirus-like sequences in the GOS metagenomic data.

osigma akashiwo virus [29] contain an intein element at the same location. These intein sequences were removed to obtain a canonical multiple alignment of the PolB sequences. This alignment confirmed the conservation of all the known catalytic residues [28] of the polymerase domain. A maximum likelihood tree obtained from the alignment strongly supported the grouping of the mimivirus PolB sequence, its homologs from the metagenomic data and the PolB sequences from CeV01, PpV01 and PoV01 (bootstrap value $=98 \%$; Fig. 3). Similar levels of bootstrap support were obtained by neighbor joining and maximum parsimony approaches (99\% and 80\%, respectively). Certain of the GOS-ORFs (nine GOS-ORFs) are more closely related to PolB's from CeV01 and/or PpV01 (bootstrap value $=100 \%$ ), while others appear to be more closely related to PolB's from PoV01 and/or mimivirus. The percentage of identical amino acid residues between mimivirus PolB sequence and its GOS homologs in Figure 3 varies from $37 \%$ to $48 \%$, suggesting a substantial level of genetic diversity of the mimivirus relatives in the sea. Mimivirus PolB sequence exhibits 41\%, 31\%, 45\% identity with the PolB sequence of the three algal viruses CeV01, PpV01, and PoV01, respectively. The phylogenetic tree presented in Figure 3 supports the monophyletic grouping for iridoviruses (100\%) as well as for poxviruses (75\%). In contrast, the inclusion of the new mimiviruslike PolB sequences in the phylogenetic analysis apparently breaks the monophyletic grouping of viruses previously classified as member of the phycodnavirus family, robustly clustering the CeV01, PpV01, and PoV01 viruses with mimivirus.

\section{Discussion}

CeV01, PpV01 and PoV01 were initially isolated from Norwegian coastal waters. An electron cryomicroscopic analysis revealed the icosahedral capsid of PpV01 particles with a maximum diameter of $220 \mathrm{~nm} \mathrm{[23].} \mathrm{Icosahedral}$ morphology was also suggested for CeV01 $(160 \mathrm{~nm})$ and PoV01 $(220 \times 180 \mathrm{~nm})$ from the observations by trans- mission electron microscopy [22]. The genomes of these viruses are composed of double-stranded DNA, with estimated sizes being 510-kb for CeV01, 485-kb for PpV01 and 560-kb for PoV01 [22,30]. The genome sizes are substantially larger than the currently sequenced largest phycodnavirus genome (i.e. 407-kb for EhV-86, [31]. Electron microscopy observations of infected cells indicate that viral assembly takes place in the cytoplasm of all three host cells [22,32]. Given these features, these three lytic algal viruses are tentatively classified as phycodnaviruses.

Previous studies have indicated a relatively close phylogenetic relationship [2] and a similarity in gene composition [10] between phycodnaviruses and mimivirus. Several phycodnaviruses exhibit the largest genome sizes (>300$\mathrm{kb})$ after mimivirus [4]. Claverie et al. have hypothesized that Phycodnaviridae is a promising source of giant viruses [4]. In this study, we present phylogenetic evidence for a close relationship between the PolB sequences of three algal viruses (CeV01, PpV01, PoV01) and mimivirus, and for the segregation of these from homologs of other known viruses. PolB is one of the NCLDV core genes, and serves as a phylogenetic marker for the classification of large DNA viruses $[33,34]$. There now seems to be a continuum between the giant mimivirus and some algal viruses at least with respect to the sequence of this essential viral enzyme. The large genome sizes of CeV01, PpV01, and PoV01 might be another indication of their close evolutionary relationship with mimivirus. Phylogenetic classification of phycodnaviruses and mimiviruses (including the split of Phycodnaviridae or merging of Mimiviridae and Phycodnaviridae) may have to be revisited based on sequence information from other genetic markers such as major capsid proteins (Larsen et al. manuscript in preparation) and other NCLDV core genes.

Our discovery of the close relationships among PolB sequences of mimivirus and the three algal viruses as well as their homologs from metagenomic data now sheds 
A

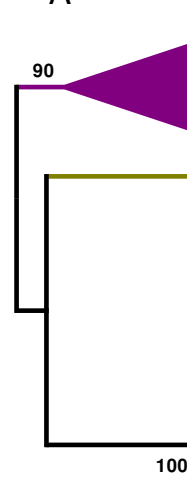

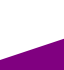

Pox

Poxviridae

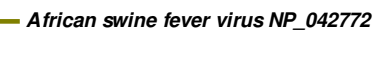

E.huxleyi virus 86 YP_293826

H akashiwo virus 1 Q91DIO

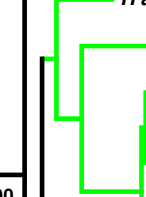

100

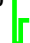

- E siliculosus virus 1 NP_077511

P.bursaria chlorella virus 1 NP_048749

P.bursaria chlorella virus NY2A YP_001497732

P.bursaria chlorella virus AR158 YP_001498560

89 P.bursaria chlorella virus FR483 YP 001426221

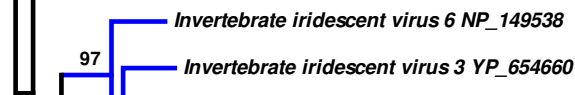

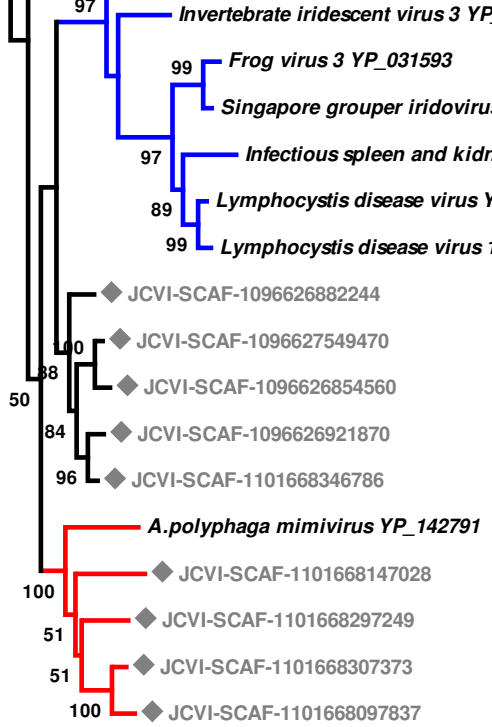

0.5
B

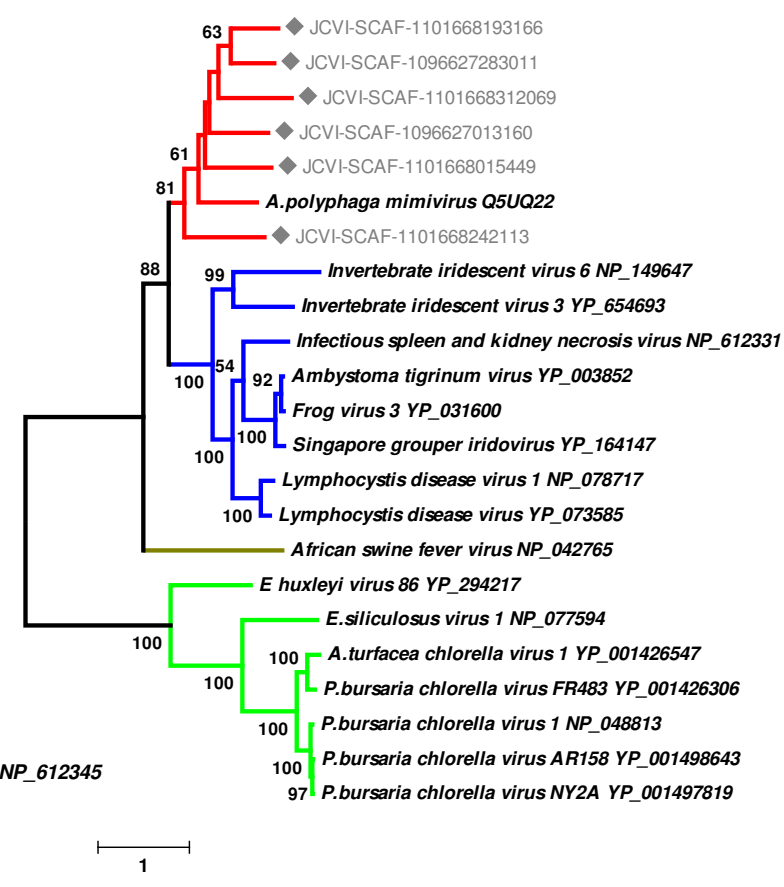




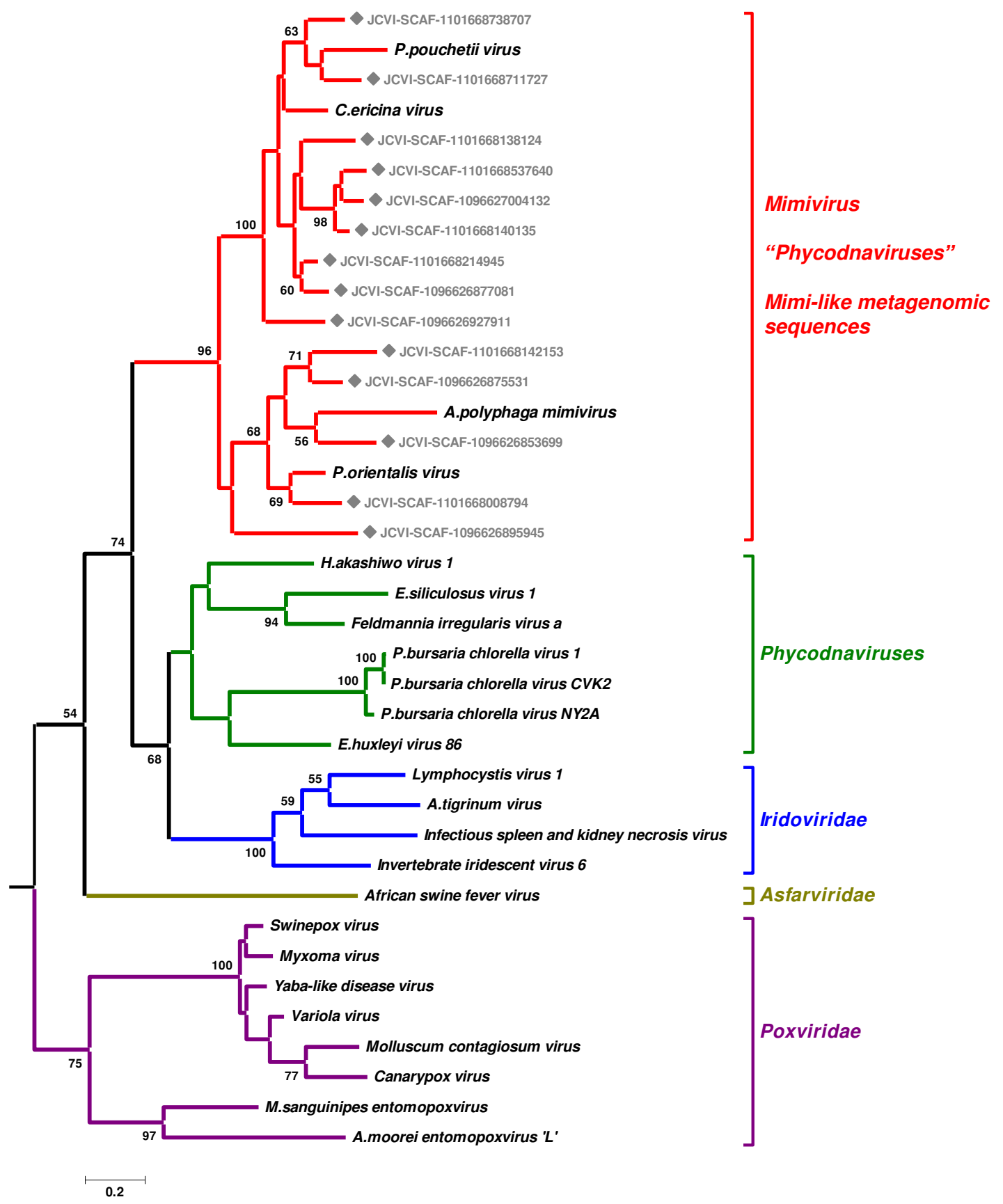

Figure 3

Maximum likelihood tree of the PoIB sequences from NCLDV and the GOS data. Nodes with rectangle marks correspond to the sequences from the GOS data. This tree is rooted by phage sequences.

If horizontal transfer of viral PolB genes does occur, it would become difficult to interpret the PolB phylogeny as representing the true relationships between viruses. However, to the best of our knowledge, no instance of lateral transfer of PolB genes between distantly related eukaryotic large DNA viruses has been documented. The determination of the whole genome sequences of CeV01, PpV01 and PoV01 would definitely help clarifying their evolutionary relationship with mimivirus.

\section{Conclusion}

Three algal viruses (CeV01, PpV01 and PoV01) possess DNA polymerase genes that are closely related to the DNA polymerase from the giant mimivirus. This suggests that 
the numerous "mimivirus-like" sequences detected in marine metagenomic data might originate from viruses infecting phytoplankton species related to $C$. ericina, $P$. pouchetii or $P$. orientalis, rather than marine amoebae. These results imply new approaches in attempting the isolation of additional, and eventually closer, relatives of mimivirus.

\section{Methods}

The scaffold sequences for the combined assembly of the GOS metagenomic data were downloaded from the CAMERA web site [35]. We extracted 21,406,171 ORFs ( $\geq$ aa) from the scaffolds using the EMBOSS/getorf program [36].

We defined "mimivirus-like ORFs" based on the following two-way BLASTP searches [37]. First, the amino acid sequences of the ORFs were searched against the UniProt sequence database release 11.3 (as of July 2007, [38]) using BLASTP (E-value $<0.001$ ). This search resulted in 6,212 ORFs with its best hit to a mimivirus protein in the database. For each of the 6,212 ORFs, we extracted a segment of the mimivirus sequence that was aligned with the ORF by BLASTP. Next, this partial mimivirus sequence was searched against the UniProt database (excluding mimivirus entries in the database). If the best score obtained by this second BLASTP search is lower than the BLASTP score obtained by the first BLASTP search, we kept the ORF as "mimivirus-like". Accordingly, we obtained 5,293 mimivirus-like ORFs. The UniProt database does not contain the three entries used for the phylogenetic study (i.e. ABU23716, ABU23717, ABU23718).

Mimivirus ORFans were defined by the lack of detectable homologs in the UniProt database using BLASTP with an E-value threshold of 0.001 .

Multiple sequence alignment was constructed using MUSCLE [39]. All the gap-containing sites in the alignment were excluded in the phylogenetic analysis. We used only the polymerase domain sequences, and removed exonuclease domain sequences. The delineation of the polymerase domains were performed using the Pfam entry PF00136 [40]. Intein sequences were also removed from Mimivirus, $\mathrm{HaV}$, CeV01 PolB sequences. Maximum likelihood phylogenetic analysis was performed using PhyML [41] with JTT substitution model and 100 bootstrap replicates. Neighbor joining analysis was performed using BIONJ [42]. The above methods are available from the Phylogeny.fr server [43]. Maximum parsimony analysis was performed using PHYLIP/PROTPARS [44].

\section{List of abbreviations used}

$\mathrm{CeV}$ : Chrysochromulina ericina virus; PpV: Phaeocystis pouchetii virus; PoV: Pyramimonas orientalis virus; NCLDV:
Nucleocytoplasmic large DNA virus; GOS: Global Ocean Sampling Expedition; PolB: type B DNA polymerase; ORF: open reading frame.

\section{Competing interests}

The author(s) declare that they have no competing interests.

\section{Authors' contributions}

AM performed the phylogenetic analyses. JBL and RAS contributed new sequence data. HO performed the analyses of the metagenomic data set. GB, JMC and HO contributed to the writing of the manuscript. All authors have read and approved the final document.

\section{Additional material}

\section{Additional file 1}

Number of Mimivirus-like sequences in the GOS metagenomic data set. The file shows the number of "mimivirus-like" ORFs that we found in the GOS metagenomic data set for each mimivirus ORF.

Click here for file

[http://www.biomedcentral.com/content/supplementary/1743422X-5-12-S1.xls]

\section{Acknowledgements}

AM is partially supported by the EuroPathoGenomics European network of excellence. This work was partially supported by Marseille-Nice Genopole and the French National Network (RNG).

\section{References}

I. La Scola B, Audic S, Robert C, Jungang L, de Lamballerie X, Drancourt $M$, Birtles R, Claverie JM, Raoult D: A giant virus in amoebae. Science 2003, 299(56I5):2033.

2. Raoult D, Audic S, Robert C, Abergel C, Renesto P, Ogata H, La Scola $B$, Suzan M, Claverie JM: The I.2-megabase genome sequence of Mimivirus. Science 2004, 306(5700): I344- I350.

3. Abergel C, Rudinger-Thirion J, Giege R, Claverie JM: Virus-encoded aminoacyl-tRNA synthetases: structural and functional characterization of mimivirus TyrRS and MetRS. J Virol 2007, 8 I (22): I 2406- I $24 \mid 7$.

4. Claverie JM, Ogata H, Audic S, Abergel C, Suhre K, Fournier PE: Mimivirus and the emerging concept of "giant" virus. Virus Res 2006, I I 7( I): I 33- | 44.

5. Claverie JM: Viruses take center stage in cellular evolution. Genome Biol 2006, 7(6): I I0.

6. Forterre P: Three RNA cells for ribosomal lineages and three DNA viruses to replicate their genomes: a hypothesis for the origin of cellular domain. Proc Natl Acad Sci U S A 2006 , I03(I0):3669-3674.

7. Koonin EV, Senkevich TG, Dolja VV: The ancient Virus World and evolution of cells. Biology direct 2006, I:29.

8. Bell PJ: Sex and the eukaryotic cell cycle is consistent with a viral ancestry for the eukaryotic nucleus. J Theor Biol 2006, 243( I):54-63.

9. Monier A, Claverie JM, Ogata H: Horizontal gene transfer and nucleotide compositional anomaly in large DNA viruses. BMC Genomics 2007, 8(1):456.

10. lyer LM, Balaji S, Koonin EV, Aravind L: Evolutionary genomics of nucleo-cytoplasmic large DNA viruses. Virus Res 2006, I I7(I): I56-184.

II. Mayo MA, Haenni AL: Report from the 36th and the 37th meetings of the Executive Committee of the International Com- 
mittee on Taxonomy of Viruses. Archives of virology 2006, I5 I(5): 103I-1037.

12. Davis CC, Latvis M, Nickrent DL, Wurdack KJ, Baum DA: Floral gigantism in Rafflesiaceae. Science 2007, 315(5820): 1812

13. Khan M, La Scola B, Lepidi H, Raoult D: Pneumonia in mice inoculated experimentally with Acanthamoeba polyphaga mimivirus. Microb Pathog 2007, 42(2-3):56-6I.

14. La Scola B, Marrie TJ, Auffray JP, Raoult D: Mimivirus in pneumonia patients. Emerg Infect Dis 2005, I I (3):449-452.

15. Berger P, Papazian L, Drancourt M, La Scola B, Auffray JP, Raoult D: Ameba-associated microorganisms and diagnosis of nosocomial pneumonia. Emerg Infect Dis 2006, I2(2):248-255.

16. Larcher C, Jeller V, Fischer H, Huemer HP: Prevalence of respiratory viruses, including newly identified viruses, in hospitalised children in Austria. Eur J Clin Microbiol Infect Dis 2006, 25(II):68I-686.

17. Suzan-Monti M, La Scola B, Raoult D: Genomic and evolutionary aspects of Mimivirus. Virus Res 2006, II 7(I): I 45-I55.

18. Khan NA: Acanthamoeba: biology and increasing importance in human health. FEMS Microbiol Rev 2006, 30(4):564-595.

19. Lorenzo-Morales J, Ortega-Rivas A, Foronda P, Martinez E, Valladares $B$ : Isolation and identification of pathogenic Acanthamoeba strains in Tenerife, Canary Islands, Spain from water sources. Parasitology research 2005, 95(4):273-277.

20. Ghedin E, Claverie JM: Mimivirus relatives in the Sargasso sea. Virol J 2005, 2:62.

21. Rusch DB, Halpern AL, Sutton G, Heidelberg KB, Williamson S, Yooseph S, Wu D, Eisen JA, Hoffman JM, Remington K, Beeson K, Tran B, Smith H, Baden-Tillson H, Stewart C, Thorpe J, Freeman J, Andrews-Pfannkoch C, Venter JE, Li K, Kravitz S, Heidelberg JF, Utterback T, Rogers YH, Falcon LI, Souza V, Bonilla-Rosso G, Eguiarte LE, Karl DM, Sathyendranath S, Platt T, Bermingham E, Gallardo V, Tamayo-Castillo G, Ferrari MR, Strausberg RL, Nealson K, Friedman R, Frazier M, Venter JC: The Sorcerer II Global Ocean Sampling expedition: northwest Atlantic through eastern tropical Pacific. PLOS Biol 2007, 5(3):e77.

22. Sandaa RA, Heldal M, Castberg T, Thyrhaug R, Bratbak G: Isolation and characterization of two viruses with large genome size infecting Chrysochromulina ericina (Prymnesiophyceae) and Pyramimonas orientalis (Prasinophyceae). Virology 200I, 290(2):272-280.

23. Yan X, Chipman PR, Castberg T, Bratbak G, Baker TS: The marine algal virus $P p V 0 I$ has an icosahedral capsid with $T=219$ quasisymmetry. J Virol 2005, 79( I 4):9236-9243.

24. Hansen PJ, Nielsen TG, H. K. Distribution and growth of protists and mesozooplankton during a bloom of Chrysochromulina spp. (Prymnesiophyceae, Prymnesiales). Phycologia 1995, 34(5):409-4I6.

25. Schoemann V, Becquevort S, Stefels J, Rousseau V, Lancelot C: Phaeocystis blooms in the global ocean and their controlling mechanisms: a review. J Sea Res 2005, 53:43-66.

26. Daugbjerg N, Moestrup O: Four new species of Pyramimonas (Prasinophyceae) from arctic Canada including a light and electron microscopic description of Pyramimonas quadrifolia sp. nov. Eur J Phycol 1993, 28(1):3-16.

27. Aure J, Rey F: Oceanographic conditions in the Sandsfjord system, western Norway, after a bloom of the toxic prymnesiophyte Prymnesium parvum Carter in August 1990. Sarsia 1992, 76(4):247-254.

28. Ogata $H$, Raoult $D$, Claverie JM: A new example of viral intein in Mimivirus. Virol $]$ 2005, 2(I):8.

29. Nagasaki K, Shirai Y, Tomaru Y, Nishida K, Pietrokovski S: Algal viruses with distinct intraspecies host specificities include identical intein elements. Appl Environ Microbiol 2005, 7 I (7):3599-3607.

30. Castberg T, Thyrhaug R, Larsen A, Sandaa RA, Heldal M, Van Etten JL, Bratbak G: Isolation and characterization of a virus that infects Emiliania huxleyi (Haptophyta). J Phycol 2002, 38(4):767-774.

31. Wilson WH, Schroeder DC, Allen MJ, Holden MT, Parkhill J, Barrell BG, Churcher C, Hamlin N, Mungall K, Norbertczak H, Quail MA, Price C, Rabbinowitsch E, Walker D, Craigon M, Roy D, Ghazal P: Complete genome sequence and lytic phase transcription profile of a Coccolithovirus. Science 2005, 309(5737): 1090-1092.
32. Jacobsen A, Bratbak G, Heldal M: Isolation and characterization of a virus infecting Phaeocystis pouchetii (Prymnesiophyceae). J Phycol 1996, 32(6):923-927.

33. Chen F, Suttle CA: Evolutionary relationships among large double-stranded DNA viruses that infect microalgae and other organisms as inferred from DNA polymerase genes. Virology 1996, 219(I): I70-178.

34. Villarreal LP, DeFilippis VR: A hypothesis for DNA viruses as the origin of eukaryotic replication proteins. J Virol 2000, 74(1 5):7079-7084.

35. Seshadri R, Kravitz SA, Smarr L, Gilna P, Frazier M: CAMERA: a community resource for metagenomics. PLOS Biol 2007, 5(3): $\mathrm{e} 75$

36. Rice P, Longden I, Bleasby A: EMBOSS: the European Molecular Biology Open Software Suite. Trends Genet 2000, 16(6):276-277.

37. Altschul SF, Madden TL, Schaffer AA, Zhang J, Zhang Z, Miller W, Lipman DJ: Gapped BLAST and PSI-BLAST: a new generation of protein database search programs. Nucleic Acids Res 1997, 25(I 7):3389-3402.

38. Wu CH, Apweiler R, Bairoch A, Natale DA, Barker WC, Boeckmann B, Ferro S, Gasteiger E, Huang H, Lopez R, Magrane M, Martin MJ, Mazumder R, O'Donovan C, Redaschi N, Suzek B: The Universal Protein Resource (UniProt): an expanding universe of protein information. Nucleic Acids Res 2006, 34(Database issue):DI87-9I.

39. Edgar RC: MUSCLE: a multiple sequence alignment method with reduced time and space complexity. BMC Bioinformatics 2004, 5(I): II3.

40. Bateman A, Birney E, Durbin R, Eddy SR, Finn RD, Sonnhammer EL: Pfam 3.I: I 3 I 3 multiple alignments and profile HMMs match the majority of proteins. Nucleic Acids Res 1999, 27(I):260-262.

41. Guindon S, Gascuel O: A simple, fast, and accurate algorithm to estimate large phylogenies by maximum likelihood. Systematic biology 2003, 52(5):696-704.

42. Gascuel O: BIONJ: an improved version of the NJ algorithm based on a simple model of sequence data. Mol Biol Evol 1997. 14(7):685-695

43. Phylogeny.fr: [http://www.phylogeny.fr].

44. Felsenstein J: PHYLIP (Phylogeny Inference Package) version 3.6b. Distributed by the author. Department of Genome Sciences, University of Washington, Seattle. 2004.
Publish with Biomed Central and every scientist can read your work free of charge

"BioMed Central will be the most significant development for disseminating the results of biomedical research in our lifetime. "

Sir Paul Nurse, Cancer Research UK

Your research papers will be:

- available free of charge to the entire biomedical community

- peer reviewed and published immediately upon acceptance

- cited in PubMed and archived on PubMed Central

- yours - you keep the copyright
BiolMedcentral 